\title{
INSALUBRE PELA PRÓPRIA NATUREZA: A BIBLIOTECA E OS RISCOS À SAÚDE DO PROFISSIONAL DA INFORMAÇÃO
}

\section{UNHEALTHY BY OWN NATURE: THE LIBRARY AND THE HEALTH RISKS OF THE INFORMATION PROFESSIONAL}

Marília Cossich Ramosa

\begin{abstract}
RESUMO
Objetivo: Tem por objetivo refletir sobre o ambiente de trabalho e a prática profissional do bibliotecário tendo em vista o surgimento de doenças ocupacionais decorrentes do exercício da profissão. Metodologia: Trata-se de uma pesquisa descritiva com abordagem qualitativa. Para a coleta dos dados foi realizado um levantamento bibliográfico em artigos de periódicos e livros. Conclusões: Estabelece relações entre a falta de políticas institucionais quanto a segurança do trabalho para os bibliotecários e o surgimento de doenças ocupacionais. Como resultado pôde-se perceber a importância da adequação do ambiente de trabalho e das práticas profissionais a fim de se eliminar e/ou diminuir a incidência de doenças ocupacionais.
\end{abstract}

Descritores: Segurança do trabalho. Bibliotecas. Doenças profissionais. Bibliotecários.

\section{INTRODUÇÃO}

Nas últimas décadas houve um crescimento exponencial no volume de conhecimento produzido pela ciência alavancado pelo avanço das tecnologias de informação. Em se tratando das bibliotecas a rotina laboral do profissional da informação foi impactada com a automação de seus serviços (década de 1990) e o consequente aumento da demanda de trabalho.

Sendo assim um desafio enfrentado por estes profissionais em decorrência destas transformações, além de o ambiente da biblioteca ser considerado insalubre por natureza, foi o aumento de doenças ocupacionais em virtude do ambiente e da rotina de trabalho. Somando-se a isto muitas

\footnotetext{
a Mestre em Biblioteconomia pela UNIRIO. Bibliotecária do Setor de Processamento Técnico da Biblioteca do IM da Universidade Federal do Rio de Janeiro (UFRJ). E-mail: marilia@im.ufr..br
} 
instituições não adotam políticas no que tange a proteção à saúde do trabalhador ou as mesmas são ineficientes, o que agrava o problema.

Uma revisão sistemática da literatura aponta para uma baixa produtividade sobre este tema, sendo um fator que acarreta a invisibilidade do fenômeno ocasionando o não reconhecimento dos problemas de saúde adquiridos pelos profissionais da informação. Percebe-se que as preocupações relacionadas ao bem-estar do profissional associadas ao ambiente de trabalho são fatores esquecidos também nas produções em Biblioteconomia. (SOUZA; SILVA, 2007).

O trabalho do profissional da informação não está inserido dentre aqueles de 'grande massa', portanto há raros textos tanto no Brasil quanto no exterior sobre a análise das funções e dos ambientes de trabalho destes profissionais. De acordo com Souza e Silva (2007) podemos verificar que:

Isso parece ter relação com a limitada visibilidade social do bibliotecário, que pode decorrer de fatores como: ser ele parte de uma profissão com pequeno contingente de profissionais, quando comparada a outras profissões do setor de ciências sociais aplicadas; advir de uma educação universitária que, no país ou no exterior, conta com pequeno número de escolas; fazer parte de uma contexto cultural em que predomina a informalidade nas transações discursivas, etc. Isso contribui para um relativo desconhecimento da população sobre essa profissão, o que, no caso brasileiro, também colabora no sentido de que seu ambiente de trabalho ainda não seja o mais apropriado em termos de proporcionar bem-estar ocupacional em todas as circunstâncias e em todas as organizações empregadoras.

Diante deste cenário uma questão se evidencia: quais os riscos ambientais de trabalho aos quais o profissional da informação está suscetível?

Esta pesquisa tem por objetivo refletir sobre o ambiente de trabalho do profissional da informação e os riscos à sua saúde aos quais está submetido. $O$ profissional da informação analisado neste estudo será o bibliotecário que atua em bibliotecas que são consideradas seu ambiente de trabalho mais tradicional.

\section{METODOLOGIA}

Trata-se de uma pesquisa descritiva com abordagem qualitativa. Para a coleta dos dados foi realizada uma pesquisa bibliográfica multidisciplinar. $\mathrm{Na}$ 
qual foram pesquisadas fontes secundárias como artigos de periódicos e dissertações.

\section{DISCUSSÃO BIBLIOGRÁFICA}

\subsection{A Biblioteca e a Profissão de Bibliotecário}

Desde o início da humanidade o homem preocupou-se em registrar o conhecimento por ele produzido. A relevância da biblioteca para a preservação e conservação do conhecimento é inquestionável sendo conferida ao bibliotecário a missão de realizar os processos de organização, preservação e disseminação de todo o conhecimento registrado. As primeiras bibliotecas, na forma como conhecemos hoje, surgiram na Mesopotâmia, no segundo milênio a.C. (RODRIGUES et al., 2013).

A biblioteca era considerada na Antiguidade apenas como um local para o depósito de livros porém com o passar dos anos esta visão foi mudando e ela passou a ser conhecida também como um ambiente de obtenção do saber. Assim como afirma Ranganathan (2009, p.26): "a biblioteca não é apenas um local que abriga uma coleção de livros que possui uma idade avançada, e os livros com o pó do desgaste do tempo". Ao longo dos anos a biblioteca tornouse a guardiã da memória e do conhecimento de uma sociedade sendo um equipamento cultural de grande importância para a educação, cultura e entretenimento da população.

No Brasil a história das bibliotecas até o início do século XIX pode ser resumida em três etapas sucessivas: inicia-se com as bibliotecas dos conventos e particulares, passa-se pela fundação da Biblioteca Nacional e chega-se até a criação da Biblioteca Pública da Bahia. A partir do século XIX o bibliotecário passa a ter como missão a promoção da leitura e a busca por leitores, entretanto - contínuo desenvolvimento técnico-científico e a consequente explosão bibliográfica que o advento da imprensa ocasionou a partir do século $\mathrm{XV}$ alteraram este papel. O bibliotecário passou a desempenhar a função de filtro que se interpõe entre a torrente de livros e o homem. Segundo Rodrigues et al. (2013, p. 85) desde então: 
O bibliotecário passa a desenvolver uma relação conflituosa com o livro, pois a quantidade de livros é tão gigantesca que supera os limites de seu tempo e de sua capacidade de assimilação do conteúdo que cada livro contém. Para dar conta dessa explosão bibliográfica, o bibliotecário passou a se preocupar mais com os processos técnicos, em especial a catalogação e a classificação, do que com os serviços aos leitores, sedimentando a imagem de um profissional tradicionalmente afundado entre livros.

O bibliotecário do século XXI surge com a sociedade da informação, na era da informação, e refere-se àqueles que têm como objeto de trabalho a informação. Por isso este profissional deve manter-se sempre atualizado, capacitar-se para desenvolver pesquisa e manusear suportes variados de informação privilegiando sempre as demandas informacionais do seu público-alvo (RODRIGUES et al., 2013).

A profissão de bibliotecário foi regulamentada no Brasil na década de 1960 por meio da lei n. 4.084/1962 (CONSELHO FEDERAL DE BIBLIOTECONOMIA, 2002). Em relação às atividades realizadas por estes profissionais podemos mencionar a definição da Classificação Brasileira de Ocupações, lançada pelo Ministério do Trabalho e Emprego em 2002, que qualifica as atividades laborativas dos bibliotecários.

De acordo com Fonseca (2007) a biblioteca é o espaço onde ocorre a busca e interação do usuário com o acervo, sendo que a informação buscada pode estar nos mais variados suportes tais como livros, periódicos, mapas, fotografias, bases de dados entre outros. Sendo assim, na biblioteca os suportes informacionais estão organizados em estantes, catalogados por assuntos e disponibilizados para atender as necessidades de um público específico.

Conforme Santos (2010) a biblioteca não deve ser compreendida apenas como um fenômeno social e cultural mas também como uma instituição social das mais complexas e importantes do sistema de comunicação humano responsável pela preservação e transmissão do conhecimento.

Neste contexto o profissional da informação é o responsável por intermediar o acesso à informação aos usuários, atuando nos processos de geração, disseminação, recuperação, gerenciamento, conservação e utilização da informação. Dentre suas atribuições estão: a catalogação, a classificação e a indexação de materiais, a administração do acervo e o auxílio as buscas dos 
usuários. Seu ambiente de trabalho mais tradicional é a biblioteca porém o bibliotecário também pode atuar em outros setores como arquivos, museus, centros de documentação, livrarias e editoras (BRAGA et al., 2018).

Com a automação dos serviços da biblioteca, por volta da década de 1980, o trabalho do bibliotecário sofreu mudanças que facilitaram sua rotina de trabalho como a busca e o acesso as informações sobre o acervo mas que também ocasionaram um impacto em sua saúde ocupacional.

As novas tecnologias de informação fizeram com que a demanda de trabalho do bibliotecário aumentasse, que em certa medida contribuiu para o surgimento de doenças ocupacionais juntamente com o ambiente já insalubre da biblioteca. A biblioteca por natureza é considerado um ambiente insalubre pois abriga um acervo suscetível a infestação de pragas (caso não haja higienização adequada) assim como o ambiente de trabalho (caso seja inadequado 0 mobiliário, a iluminação, a temperatura) dentre outros fatores.

Cabe ressaltar que no mundo contemporâneo com toda a evolução das tecnologias de informação, o bibliotecário está cada vez mais vulnerável a adquirir patologias no ambiente profissional. A maioria das ações das empresas eram voltadas para o trabalho e não para o trabalhador como identifica o autor e expõe a importância de uma nova relação:

A palavra de ordem é o comprometimento organizacional, uma
variável que ganha importância nos estudos da psicologia
organizacional nos anos 80 , auge do movimento de globalização
e liberalização da economia. Tais estudos se situam no âmbito
do comportamento humano no trabalho, mais especificamente
em uma subárea denominada atitudes em relação ao trabalho e
constituem-se em tecnologias gerenciais para lidar com o
elemento humano nas organizações. Busca-se, com as
pesquisas sobre comprometimento, encontrar relações entre os
diversos comprometimentos que o trabalhador pode
experimentar e como eles se articulam na determinação do seu
comportamento no trabalho (ALVIM, 2000, p. 124).

Portanto diante da mudança no paradigma da profissão nos últimos anos e com a inserção das novas tecnologias o profissional bibliotecário sofreu diversas mudanças em sua rotina laboral, que contribuíram para o aumento de problemas relacionados a sua saúde somados aos riscos do ambiente de trabalho. 


\subsection{Riscos Ambientais de TrabalHo}

A apreensão do homem com possíveis doenças ocasionadas em função do exercício profissional e o ambiente laboral remonta para a Antiguidade. De acordo com a literatura esta inquietação já era observada nos papiros egípcios e posteriormente na tradição judaica e no mundo greco-romano. Naquela época podia-se observar também que os ambientes laborais acarretavam diversos tipos de lesões físicas nos trabalhadores bem como doenças mentais graves.

Os problemas de saúde decorrentes do ambiente e das atividades de trabalho remontam para a Antiguidade porém a preocupação com a saúde e qualidade de vida do trabalhador é uma temática relativamente recente na qual estudos datam da segunda metade do século XX e início do XXI.

A questão das doenças ocupacionais foi objeto sistemático de estudos de áreas do conhecimento diversas tais como a Sociologia, o Serviço Social, a Medicina do Trabalho, as Engenharias, entre outras, enquanto a História, especialmente no Brasil, com raras exceções, se furtou frente a este desafio (SILVA, 2011). Além da Sociologia e do Serviço Social serem mais próximas da História outras áreas do conhecimento surgiram como resposta aos embates provocados pelas novidades trazidas pela Revolução Industrial também trataram deste problema no Brasil (DWYER, 2006 apud SILVA, 2011). Os estudos de Ergonomia, de Medicina, de Psicologia do Trabalho e de Engenharia de Segurança se desenvolveram com o objetivo de identificar causas específicas de acidentes, preveni-los e remediá-los, revestindo-se de uma tecnicidade objetiva e pretensamente despolitizada (SILVA, 2011).

Uma doença ocupacional ou profissional está definida no artigo 20, I da Lei n. 8.213 de 24 de julho de 1991 como a enfermidade produzida ou desencadeada pelo exercício do trabalho peculiar a determinada atividade e constante da relação elaborada pelo Ministério do Trabalho e da Previdência Social. Já o ambiente de trabalho é composto por um conjunto de fatores e quando um destes ou um conjunto deles foge ao controle seja pelos níveis permitidos ou pelos processos que desencadeiam torna o ambiente de trabalho suscetível ao desenvolvimento das chamadas doenças ocupacionais (SOUZA 
et. al., 2016).

Um dos profissionais mais atingidos por doenças ocupacionais são 0 bibliotecário e o técnico de biblioteca acometidos principalmente por doenças ocupacionais relacionadas a riscos químicos, físicos, ergonômicos, biológicos e mecânicos que estão afetando cada vez mais a saúde física e mental destes profissionais. Os riscos biológicos e mecânicos são os mais frequentes no ambiente de trabalho dos profissionais da informação e independentemente do tipo de risco é preciso conhecê-los para então elaborar ações para sua eliminação e/ou minimização. Para Souza e Silva (2007, p. 141) em relação aos riscos mecânicos temos:

A preocupação com a Ergonomia surge aqui não simplesmente como uma iniciativa exclusiva daquele que emprega profissionais bibliotecários, mas é sobremaneira, responsabilidade também de cada profissional e de sua classe, como questão ética, bem como um dever para que cada membro da classe zele para que o ambiente de trabalho de cada bibliotecário não venha a ser uma fonte de traumas físicos e mentais.

Os ambientes fechados, especialmente as bibliotecas, apresentam uma ampla diversidade de fontes poluentes por serem ambientes multifacetados pois contém elementos como temperatura, iluminação e ruídos sonoros. De acordo com o autor:

A forma de ocupação destes ambientes favorece os processos de poluição, impondo frequentemente o acúmulo de grandes quantidades de papéis além de outras características culturais que estão transformando estes ambientes de trabalho em locais insalubres, os quais vêm proporcionando a seus usuários uma qualidade de vida insatisfatória (SIQUEIRA, 1998, p. 244).

O ambiente da biblioteca pode apresentar pouca ou nenhuma ventilação o que favorece o aparecimento de umidade sendo este um fator prejudicial à saúde dos trabalhadores muitas vezes expostos sem nenhuma proteção, o que pode impactar em sua saúde, bem-estar e produtividade. Além disso a umidade pode conter a presença de microrganismos como bactérias, fungos e vírus que podem ser encontrados em livros e mobiliários muitas vezes com ação patogênica (BRAGA et al., 2018).

Sendo assim temos diversos riscos ambientais de trabalho que apresentam-se sob a forma de agentes causadores de doenças ocupacionais e 
que geralmente dependem da frequência com que ocorrem e do histórico de saúde do bibliotecário, das condições de saúde, da idade, sexo, entre outros. Os fatores podem ser:

- Físicos: ruídos sonoros, temperaturas extremas (frio e calor), pressão atmosférica anormal, umidade, entre outros;

- Químicos: gases, vapores, poeira, produtos químicos em geral etc;

- Ergonômicos e Psicossociais: computadores e mobiliário inadequados levando a posturas incorretas; locais adaptados com más condições de iluminação, ventilação e de conforto; transporte de peso, monotonia ou ritmo de trabalho excessivo, exigências de produtividade, relações de trabalho despóticas, assédio moral;

- Biológicos: vírus, bactérias, parasitas, fungos, protozoários, bacilos etc;

- Mecânicos: ligados à proteção das máquinas, arranjo físico, ordem e limpeza do ambiente de trabalho, sinalização, que podem levar a acidentes de trabalho (BRASIL, 2001).

A saúde dos trabalhadores de uma forma geral vem sendo um tema bastante discutido nos últimos anos devido ao grande número de licenças médicas, afastamentos, tratamentos médicos, fisioterapias e até aposentadorias precoces. As organizações tiveram que se adaptar com o surgimento de patologias decorrentes do trabalho tornando-se um problema inclusive de saúde pública. A qualidade de vida do trabalhador em seu ambiente de trabalho tem sido uma preocupação de muitas empresas pois afeta diretamente a produtividade e o desempenho impactando nos resultados da organização e gerando custos para o empregador.

\subsection{Medicina, Segurança do Trabalho e Qualidade de Vida}

A Segurança do Trabalho está impregnada na história mundial porém não era reconhecida por este nome. Um marco para a sua evolução foi durante a Revolução Industrial mas encontram-se resquícios muito antes desse fato histórico. Num mundo com o mercado de trabalho cada vez mais competitivo parte-se da premissa de que a Segurança do Trabalho ainda agrega valor 
organizacional e é colocada em segundo plano sendo apenas observados os requisitos mínimos para satisfazer as exigências legais (BRISTOT, 2019).

Segundo Bristot (2019) a Segurança do Trabalho pode ser compreendida como um conjunto de medidas adotadas com o objetivo de minimizar ou eliminar os acidentes de trabalho, doenças ocupacionais, bem como proteger a integridade e a capacidade de trabalho do trabalhador. No Brasil a legislação de Segurança do Trabalho engloba as Normas Regulamentadoras, as Leis complementares, com suas Portarias e Decretos e as Convenções Internacionais de Trabalho.

O médico italiano Bernardino Ramazzini é considerado o pai da Medicina do Trabalho por seu livro "As doenças dos trabalhadores" publicado em 1700. Nele o autor relaciona 54 profissões e descreve os principais problemas de saúde apresentados pelos trabalhadores destacando a necessidade de os médicos conhecerem a ocupação atual e pregressa de seus pacientes para um diagnóstico correto e a adoção de procedimentos adequados. Muitas dessas descrições são baseadas nas próprias observações clínicas do autor, o qual nunca se esquecia de perguntar ao seu paciente: "Qual a sua ocupação?". O trabalho pode sim causar danos ao trabalhador porém é função dos profissionais de Segurança e Medicina do Trabalho minimizar ou neutralizar esse fator (BRISTOT, 2019). Enquanto especialidade médica a Medicina do Trabalho surge na Inglaterra na primeira metade do século XIX, com a Revolução industrial (ASSOCIAÇÃO NACIONAL DE MEDICINA DO TRABALHO, [20??].

No Brasil a história da proteção contra acidentes e doenças ocupacionais caminha a passos lentos se compararmos aos países mais desenvolvidos e que possuem uma história de industrialização mais antiga.

A melhor forma de se evitar um acidente de trabalho e a ocorrência de doenças é por meio da prevenção. Diante dessa visão prevencionista o Brasil deixou de ser o recordista mundial em acidentes de trabalho (em 1994) porém os índices ainda são alarmantes. Os acidentes além de causarem transtornos para quem os sofre também expõe a danos a empresa e a família do acidentado. As medidas de prevenção à saúde do trabalhador são ferramentas importantes com a finalidade de reduzir os riscos e acidentes de trabalho. Existem alguns 
procedimentos de obrigatoriedade pela legislação porém cada empresa pode através de procedimentos internos, criar ferramentas próprias e intensificar as inspeções e treinamentos com o foco na prevenção (BRISTOT, 2019).

É necessário frisar a importância da adoção de medidas protetivas pelas organizações para com seus colaboradores. Dentre tais medidas, temos:

- Medidas de proteção coletivas;

- Medidas de organização do trabalho;

- Medidas de proteção individual.

De acordo com Souza et. al. (2016) a Segurança do Trabalho engloba diversos fatores que devem ser combinados com o intuito de prevenir e/ou evitar acidentes no ambiente de trabalho bem como doenças ocupacionais. A combinação destes é de extrema relevância em qualquer ocupação juntamente com o empenho dos funcionários e da organização sendo possível atender a todas as exigências e obter um equilíbrio que favoreça ambas as partes.

A importância da proteção à saúde dos trabalhadores motivou a criação de duas grandes organizações em âmbito mundial: a Organização Internacional do Trabalho (OIT) em 1919 e a Organização Mundial de Saúde (OMS) em 1948. Juntos esses dois órgãos estabeleceram em 1950 o objetivo da Saúde Ocupacional: adaptar o trabalho ao homem e cada homem à sua atividade (ASSOCIAÇÃO NACIONAL DE MEDICINA DO TRABALHO, [20??].

No Brasil em 1921 foi criada a Inspeção do Trabalho e com a reforma constitucional de 1926 foi estabelecida a competência de legislar para a União. Em 1931 durante o governo do presidente Getúlio Vargas foi criado o Departamento Nacional do Trabalho com a função de fiscalizar o cumprimento de leis sobre acidentes laborais, jornada, férias etc. Em 1943 surge no Brasil a Consolidação das Leis do Trabalho e com ela as primeiras referências à higiene e segurança no trabalho.

$\mathrm{Na}$ década de 1940 também emergem as Comissões Internas de Prevenção de Acidentes organizadas pelas empresas. Em 1947 a Organização Internacional do Trabalho adota a Convenção no 81 que estabelece que cada membro da organização deve ter um sistema de inspeção de trabalho nos estabelecimentos industriais e comerciais. A experiência dos países 
industrializados transformou-se na Recomendação no 112 de 1959 estabelecida pela OIT que tratava dos "Serviços de Medicina do Trabalho". Posteriormente ela foi substituída pela Convenção no 161 da OIT de 1985 e sua respectiva Recomendação de № 171. No fim da década de 1960 a Medicina do Trabalho já contava com uma legislação específica que melhorou sua fiscalização. O setor estava se ampliando e os médicos brasileiros relacionados à área que compareciam aos congressos internacionais sentiram a necessidade de uma associação onde pudessem se reunir para atualizar e trocar conhecimentos na área da saúde ocupacional.

Segundo Gioda e Aquino Neto (2003) em 1957 a comissão mista da Organização Internacional do Trabalho (OIT) e da Organização Mundial da Saúde (OMS) na Conferência Internacional del Trabajo (1959) definiu os objetivos sobre saúde ocupacional:

A saúde ocupacional tem como finalidade incentivar e manter o
mais elevado nível de bem-estar físico, mental e social dos
trabalhadores em todas as profissões; prevenir todo o prejuízo
causado à saúde destes e pelas condições de seu trabalho;
protegê-los em seu serviço contra os riscos resultantes da
presença de agentes nocivos à sua saúde; colocar e manter o
trabalhador em um emprego que convenha às suas aptidões
fisiológicas e psicológicas.

Já a qualidade de vida no trabalho foi inserida no contexto organizacional e tornou-se objeto de estudo na academia no início de 1950 por uma abordagem sociotécnica mas até agora as tendências e os desafios modernos do desenvolvimento da sociedade determinam o interesse contínuo por este problema (KLEIN; PEREIRA; LEMOS, 2019).

Segundo os autores Klein, Pereira e Lemos (2019) os funcionários são de extrema importância numa organização como vermos a seguir:

Os funcionários são as "engrenagens" das organizações e, por meio de habilidades, técnicas, conhecimentos e trabalho, geram o bem ou serviço que permite a elas atingir os objetivos perante a sociedade e sobreviver. O desenvolvimento das organizações depende das pessoas envolvidas para o alcance da missão, das metas e dos resultados.

A qualidade de vida no ambiente de trabalho depende de diversos fatores seja de ordem física e/ou emocional. Podemos destacar como fatores físicos adequados: o espaço físico, ergonomia dos mobiliários, condições de higiene 
pessoal e de alimentação, acessibilidade, bem como os fatores de origem emocional como a motivação e a valorização do funcionário. Estes fatores são importantes para promover a integração do trabalhador junto à organização, conforme ressalta Moreno (1991, p. 62):

Qualidade de vida no trabalho não se determina somente por características pessoais do trabalhador, tais como necessidades, expectativas e valores, ou pelas características situacionais, tais como, tecnologia, sistemas de recompensa, motivação e análise econômica, mas pela integração destes dois tipos de fatores: indivíduo/organização.

A incidência de problemas de saúde ocupacional referidos pela OMS em diversas áreas destaca aquelas ligadas às novas tecnologias de informação e automação que hoje são instrumentos e fazem parte do ambiente de trabalho do bibliotecário (SOUZA, 2007). Neste contexto uma pesquisa realizada aponta que:

As doenças relacionadas ao stress e à fadiga física e mental também são apontadas por especialistas como as que mais afetam os trabalhadores apesar da subnotificação dos casos. É o que aponta uma pesquisa realizada em 2002 pelo Laboratório de Saúde do Trabalhador da UnB a partir de dados fornecidos pelo INSS. O estudo mostrou que bibliotecários e profissionais de saúde são os que mais se afastam por causa de doenças mentais (DOENÇAS..., 2004).

Sendo assim é preciso conhecer os riscos potenciais à saúde do profissional bibliotecário a fim de se traçar estratégias que levem a promoção de seu bem-estar e qualidade de vida no ambiente de trabalho.

\section{CONSIDERAÇÕES FINAIS}

De acordo com o que foi observado os bibliotecários estão expostos e vulneráveis em seu ambiente de trabalho mais tradicional, a biblioteca, aos mais diversos fatores de risco à sua saúde, dentre eles os riscos químicos, físicos, ergonômicos, psicossociais, biológicos e mecânicos. Por se tratar de um ambiente fechado e muitas vezes com pouca ventilação a biblioteca torna-se um local propício para a proliferação de bactérias dentre outros diversos agentes causadores de patologias. Somando a isso temos a prática laboral do bibliotecário (catalogação, classificação, indexação), ou seja, uma prática 
repetitiva e que utiliza ferramentas tecnológicas (como o smartphone e 0 computador) que podem acarretar problemas posturais e ergonômicos.

A ausência de políticas governamentais, de diretrizes institucionais, a falta de informação dos próprios bibliotecários quanto a proteção a sua saúde no ambiente de trabalho, a pouca visibilidade da profissão e o pouco interesse do Estado nas bibliotecas são fatores que contribuem para a invisibilidade do problema porém é preciso uma maior conscientização por parte das autoridades competentes e ações mais efetivas junto aos bibliotecários.

A falta de ações protetivas que visem fomentar a saúde do bibliotecário em seu ambiente de trabalho pode acarretar um maior número de profissionais doentes, licenças médicas e a solicitações de afastamento do trabalho. É preciso políticas institucionais para que haja adequação do espaço e das atividades laborais além de práticas que auxiliem na qualidade de vida do colaborador como a ginástica laboral.

Espera-se que este estudo possa trazer à luz a importância da Segurança do Trabalho para a adequação do ambiente laboral e a utilização de medidas protetivas junto aos bibliotecários. Cabe ressaltar o papel da qualidade de vida no trabalho e os cuidados que todos, inclusive os bibliotecários, devem ter em relação à sua prática profissional e que possa fomentar a continuidade de estudos nesta área.

\section{REFERÊNCIAS}

ALVIM, M. B. Contato e cultura organizacional: ensaio para um modelo psicológico de análise organizacional na perspectiva da abordagem gestáltica. 2000. 263 f. Dissertação (Mestrado em Psicologia) - Instituto de Psicologia, Universidade de Brasília, Brasília, 2000.

ASSOCIAÇÃO NACIONAL DE MEDICINA DO TRABALHO. História da Medicina do Trabalho, São Paulo, [20??]. Disponível em:

https://www.anamt.org.br/portal/historia-da-medicina-do-trabalho. Acesso em: 02 dez. 2020.

BRAGA, Rogério de $S$. et. al. Prevalência de sintomas respiratórios em servidores de bibliotecas de uma universidade pública. Revista de Saúde Pública do Paraná, Paraná, v.1, n.1, p. 74-82, 2018. 
BRASIL. Ministério da Saúde. Doenças relacionadas ao trabalho: manual de procedimentos para os serviços de saúde. Brasília: Ministério da Saúde, 2001.

BRISTOT, Vilson M. Introdução à Engenharia de Segurança do Trabalho. Criciúma, SC: UNESC, 2019.

CONSELHO FEDERAL DE BIBLIOTECONOMIA. Resolução n. 42, de 11/01/2002: Código de Ética Profissional do Bibliotecário. 2002.

DOENÇAS ocupacionais matam bibliotecários. Jornal do Brasil, Rio de Janeiro, 9 jan. 2004. Disponível em:

http://www.ofaj.com.br/noticias_conteudo.php?cod=43. Acesso em: 11 jun. 2021.

DWYER, T. Vida e morte no trabalho. São Paulo: Multiação Editorial; Campinas: Editora da Unicamp, 2006.

FONSECA, Edson Nery da. Introdução a Biblioteconomia. 2. ed. Brasília: Briquet de Lemos, 2007.

GIODA, A.; AQUINO NETO, F. R. Considerações sobre estudos de ambientes industriais e não industriais no Brasil: uma abordagem comparativa. Cad.

Saúde Pública, Rio de Janeiro, v. 19, n. 5, p. 1389-1397, set./out., 2003.

KLEIN, Leander L.; PEREIRA, Breno A. D.; LEMOS, Ricardo B. Qualidade de vida no trabalho: parâmetros e avaliação no serviço público. RAM. Revista. Adm. Mackenzie, São Paulo, v. 20, n. 3, 2019.

MORENO, N. A. Qualidade de vida no trabalho: uma análise das características da tarefa de profissionais bibliotecários atuantes em bibliotecas universitárias. 1991. 202 f. Dissertação (Mestrado em Ciência da Informação) - Escola de Ciência da Informação, Universidade Federal de Minas Gerais, Belo Horizonte. 1991.

ORGANIZAÇÃO INTERNACIONAL DO TRABALHO. Recomendación sobre los servicios de Medicina del Trabajo en los lugares de empleo (Recomendación no 112 de la OIT adoptada en 24 de junio de 1959). In: Convenios y recomendaciones (1919-1966). Genebra, 1966. p. 1054-8. 46.

RANGANATHAN, S.R. Cinco leis da biblioteconomia. Brasília, DF: Briquet de Lemos, 2009.

RODRIGUES, Mara Eliane F. et al. A biblioteca e o bibliotecário no imaginário popular. Biblionline, João Pessoa, v. 9, n.1, p. 82-95, 2013.

SANTOS, Josiel M. Bibliotecas no Brasil: um olhar histórico. Revista Brasileira de Biblioteconomia e Documentação, Nova Série, São Paulo, v.6, n.1, p. 5061, jan./jun. 2010. 
SILVA, Ana Beatriz R. B. Acidentes de trabalho e processos de reabilitação profissional: elementos reveladores das condições de trabalho e das relações produtivas no Brasil. In: Simpósio Nacional de História, 26., 2011, São Paulo. Anais...São Paulo, 2011.

SIQUEIRA, Luís Fernando de G. O controle de qualidade do ar de interiores e a saúde ocupacional. In: VIEIRA, Sebastião Ivone (org.). Medicina básica do trabalho. Curitiba: Gênesis, 1998. v. 5, p. 241-245.

SOUZA, Ana Beatriz B. et. al. Gestão da segurança de trabalho: análise dos riscos de acidentes em uma microempresa no setor de panificação localizada na cidade de João Pessoa-PB. In: Encontro Nacional de Engenharia de Produção. 36., 2016, João Pessoa/PB. João Pessoa, 2016.

SOUZA, F. C.; SILVA, P. S. O trabalho do bibliotecário e os riscos potenciais a sua saúde integral em torno do campo da ergonomia. Em Questão, Porto Alegre, v.13, n.1, p. 127-146, jan./ jun. 2007.

\title{
UNHEALTHY BY OWN NATURE: THE LIBRARY AND THE HEALTH RISKS OF THE INFORMATION PROFESSIONAL
}

\begin{abstract}
Objetive: It aims to reflect on the librarian's work environment and professional practice with a view to the emergence of occupational diseases arising from the exercise of the profession. Methodology: It is a descriptive research with a qualitative approach. For data collection, a bibliographical survey was carried out on articles in periodicals and books. Conclusions: It establishes relations between the lack of institutional policies regarding job security for librarians and the emergence of occupational diseases. As a result, it was possible to perceive the importance of adapting the work environment and professional practices in order to eliminate and / or decrease the incidence of occupational diseases.
\end{abstract}

Descriptors: Workplace safety. Libraries. Professional diseases. Librarians.

\section{NO SALUDABLE POR PROPIA NATURALEZA: LA BIBLIOTECA Y LOS RIESGOS PARA LA SALUD DEL PROFESIONAL DE LA INFORMACIÓN}

\section{RESUMEN}

Objetivo: Tiene como objetivo reflexionar sobre el clima laboral y la práctica profesional del bibliotecario ante la aparición de enfermedades profesionales derivadas del ejercicio de la profesión. Metodología: Se trata de un estudio descriptivo con enfoque cualitativo. Para la recolección de datos se realizó un relevamiento bibliográfico de artículos en 
revistas y libros. Conclusiones: Establece relaciones entre la falta de políticas institucionales en materia de seguridad laboral para los bibliotecarios y la aparición de enfermedades ocupacionales. Como resultado, se pudo percibir la importancia de adecuar el clima laboral y las prácticas profesionales para eliminar y / o disminuir la incidencia de enfermedades ocupacionales.

Descriptores: Seguridad del trabajo. Bibliotecas. Enfermedades profesionales. Bibliotecarios.

Recebido em: 24.02.2021

Aceito em: 30.04 .2021 